Slater, E.C. 2003. Metabolic gardening. Nature 422: 816-817.

Weber, B. 1991. Glynn and the conceptual development of the chemiosmotic theory: A retrospective and prospective view. Bioscience Reports 11: 577-617.

Weber, M. 2002a. Theory testing in experimental biology: The chemiosmotic mechanism of ATP synthesis. Studies in History and Philosophy of Biolog: The che Weber, M. 2002b. Incommensurability and theory comparison in experimental biology. Biology and Philosophy 17: 155-169.

Wolpert, L.' 1969. Positional information and the spatial pattern of cellular differentiation. Journal of Theoretical Biology 25: 1-47.

\section{One Cognitive Style Among Others: \\ Towards a Phenomenology of the Lifeworld and of Other Experiences}

\section{Gregor Schiemann}

Abstract In his pioneering sociological theory, which makes phenomenological concepts fruitful for the social sciences, Alfred Schütz has laid foundations for a characterization of an manifold of distinct domains of experience. My aim here is to further develop this pluralist theory of experience by buttressing and extending the elements of diversity that it includes, and by eliminating or minimizing lingering imbalances among the domains of experience. After a critical discussion of the criterion-catalogue Schütz develops for the purpose of characterizing different cognitive styles, I move on to examine its application to one special style the lifeworld. I appeal, on the one hand, to Husserl's characterization of the lifeworld as a world of perception, and on the other hand to the layer-model of the lifeworld developed by Schütz and Thomas Luckmann. A consequence of this approach is that the lifeworld appears as a socially definable context that is detached from other experiences but on an equal footing with them with respect to their claim of validity. The term "lifeworld" does not denote a category that encompasses culture or nature but refers to a delimited action-space. Finally, I draw upon Schütz's criterion-catalogue to characterize two domains of experience outside of the lifeworld, which play a central role for the process of differentiation of experience in modernity and for the phenomenological analysis of types of experience: experimental science and subjectivity.

G. Schiemann (四)

Philosophisches Seminar \& IZWT, Bergische Universität Wuppertal,

Gaußsur. 20, D-42119 Wuppertal, Germany

e-mail: schiemann@uni-wuppertal.de 


\section{Introduction}

In his pioneering sociological theory, which makes phenomenological concepts fruitful for the social sciences, Alfred Schütz has laid the foundations for a characterization of a manifold of distinct domains of experience.' Alongside science and the lifeworld, one can distinguish among others the domains of dreams, fantasies, religious practices, children's play and insanity. ${ }^{2}$ Schütz characterizes these different domains by attributing to each its own distinctive "cognitive style" [Erkenntnisstil]. His understanding of "cognitive" [erkenntnismäßig] is expressed by his view that knowledge is experience that we take to be real. ${ }^{3}$ "Cognitive," here, does not refer to justified belief but, on the contrary, to beliefs that are assumed not to require justification because the reality of their objects is taken to be sufficiently firm. ${ }^{4}$

My aim here is to further develop the pluralist theory of experience by buttressing and extending the elements of diversity that it includes, and by eliminating or minimizing lingering imbalances among the domains of experience. One of the achievements of Schütz's social phenomenology is that the lifeworld, which remains the most socially important non-scientific domain of experience, has been established as an object of enquiry for sociology. ${ }^{5}$ Following Edmund Husserl's lifeworld analysis, he ascribes a foundational status to this domain, which is an ineliminable determinant of all other experiences-partly just as a presupposition, partly as a fundamental, universal structural property.

Schütz justifies the privileging of the status of the lifeworld by appealing to its character as a world of working. "Working" [Wirken] refers to all bodily movements performed to carry out "action in the outer world, based upon a project,"6 which are centered around objects lying within the perceptual field of an individual. The core of the lifeworld includes the telephone that an individual uses, for example, as well as the voice of her interlocutor, but not the interlocutor herself Cognitive styles outside of the lifeworld, in contrast, are primarily characterized by forms of action that are directed not toward objects of perception but toward past impressions, present products of imagination, or abstract entities. They rest upon different background presuppositions than the lifeworld, follow from divergen social relations, and stand at a certain distance from the demands of everyday life.

In granting a special status to the lifeworld, Schütz invests his conception with an absolute claim to validity, for his conception of the lifeworld refers to an historically

'On Schütz's sociology, see Natanson (1970); List and Srubar (1988); Embree (1999).

${ }^{2}$ Schütz (1971), 266

${ }^{3}$ Ibid., 265.

${ }^{4}$ The foundation for this approach are spelled out in "On Multiple Realities" (1945), and "Symbol, Reality, and Society" (1955), in: Schütz (1973), $207 \mathrm{ff}$. and $287 \mathrm{ff}$.

${ }^{5}$ On Schütz's theory of the lifeworld, cf. Grathoff and Sprondel (1979); Srubar (1988); Endress Psathas and Nasu (2004).

${ }^{6}$ Schütz (1971), Vol. 1, 243. and culturally invariant structure, without which human life and its various modes of experience would be unimaginable. ${ }^{7}$ One potential advantage of assuming such a universal matrix is that it could conceptually do justice to the relatively inalterable basic conditions of human life that may obtain.

If, on the other hand, one conceives of the cognitive styles as products of a typically modern process of differentiation of experiences, it is no longer possible to regard the lifeworld as an unqualified point of reference. Contemporary nonlifeworld cognitive styles are-I would submit-no longer as integrated within the lifeworld as they once were. Instead, they have become autonomous and partially professionalized, and attained an influence as such upon the lifeworld. Artistic, religious, scientific and other modes of experience outside of the lifeworld make the lifeworld appear to be unreal. Along with the lifeworld, they form a pluralist structure in which different domains border on each other and determine individuals' lives with specific intensities and durations. As a rule, individuals are not simultaneously in different domains of experience. Action in the lifeworld does not leave space for scientific work; dream-worlds extinguish waking consciousness; religious practice is not normally acquainted with the open-endedness of fantasy etc. The switch from one domain to another, which can already take place several times during one single day, implies the possibility of boundary experiences.

Correcting Schütz's conception of cognitive styles makes it possible to distinguish among various autonomous domains of experience. The dissolution of the foundational status of the lifeworld leads to a manifold of equally justified contexts, which represent the plurality of experiences that is characteristic of modernity. The non-lifeworld experiences mentioned by Schütz can be supplemented by further cognitive styles belonging, for example, to professional domains, to more finely differentiated scientific domains of experience, and to the public domain as a generally accessible sphere of societal communication, the objects of which are, to speak with Kant, "whatever necessarily interests everyone,"8 or subjectivity as an experience in which a subject's attention is directed toward its own conscious events or conscious states.

Schütz developed a catalogue of criteria for characterizing different cognitive styles. There are only a few, easily corrected, places where the catalogue reflects Schütz's privileging of the lifeworld. Section 1 will be devoted to presenting a modified version of the catalogue and illustrating it with examples. Then I take a closer look at its application to the lifeworld. I will be drawing, on the one hand, upon Husserl's definition of the lifeworld as a world of perception, and on the other hand on Schütz's and Thomas Luckmann's leveled model of the lifeworld. Consequently, the lifeworld appears as a socially bounded context that is distinct from other, equally valid, experiential domains. The term "lifeworld," then, does not refer to a category that encompasses the entirety of nature and culture, but to a restricted space of action in (next section). Finally, I will use Schütz's catalogue of criteria to characterize two

Cf. Heller (1986), 154

${ }^{8}$ Kant (1900 ff.), Vol. V, B 868 
non-lifeworldly domains of experience that play an prominent role in the modern process of differentiation of experience and for the phenomenological analysis of types of experience: experimental natural science and subjectivity (Sect. 3).

\section{Schütz's Conception of Cognitive Styles}

A "certain set of our experiences" qualifies as "a finite province of meaning" according to Schütz, "if all of them show a specific cognitive style and are-with respect to this style - not only consistent in themselves but also compatible with one another." Schütz can refer to a domain of meaning as "finite" because the condition of compatibility does not apply among cognitive styles: "that which is compatible with the province of meaning $\mathrm{P}$ be also compatible within the province of meaning Q." ${ }^{10}$ For Schütz, it is by virtue of the lifeworld that communication among domains of meaning is nevertheless possible."

The expression "cognitive style" makes it clear that Schütz is not so much interested in the content as in the form of knowledge. The term "cognitive" does not refer only to true beliefs but also to "valid as well as the invalidated [experiences],"' insofar as they exhibit the same style and are thus held with conviction to be real. The exclusive restriction to domains of meaning, however, invests the concept of knowledge with a statical character that underestimates the significance of boundary experiences, which alone enable the transformation of the conditions for the constitution of meaning. If one presupposes a division among domains of meaning, experiences arising from an overlap of cognitive styles can result either from the transgression or from the dissolution of borders. Schütz describes such experiences with a terminology that is also suitable for the transition between incommensurable worlds. Thus, the shift between domains of meaning does not occur gradually but suddenly, and is connected with an emotional shudder that Schütz compares with "Kierkegaard's experience of the 'instand' as the leap." ${ }^{13}$ Among other things, the "shock of falling asleep as the leap into the world of dreams; the inner transformation we endure if the curtain in the theater rises [...]; the radical change in our attitude if, before a painting, we permit our visual field to be limited by what is within the frame [...], our quandary, relaxing into laughter, if, in listening to a joke, we are for a short time ready to accept the fictitious world of the jest as a reality."14

${ }^{9}$ Schütz (1971), Vol. 1, 264.

${ }^{10}$ Ibid., 397 (267).

"Ibid., 296ff., 392 and 395.

${ }^{12}$ Ibid., 265.

${ }^{13}$ Ibid., 266 (267).

${ }^{14}$ Ibid., 266 (397f.)
In order to make it possible to characterize conceptually "at least some of the features" 15 of the cognitive styles specific to domains of meaning, Schütz formulated his catalogue of criteria. As already noted, I will be making some modifications to the catalogue that result from criticism of the foundational status Schütz attributed to the lifeworld. In its social-phenomenological orientation, the catalogue presupposes an egological structure that rests upon subjective experience (which Schütz does not invest with a specific cognitive style), and then integrates phenomena of intersubjectivity. The catalogue of criteria includes six features, the concise definitions of which are supplemented by Schütz with examples to illustrate their relationship with the domains of meaning. ${ }^{16}$

1. The foundational criterion, modeled upon Bergson's "attention à la vie," is the so-called "tension of consciousness," 17 which is understood as an "orienting toward and attending to life."18 Schütz distinguishes various intensities of attention, as well as various resultant degrees of reality. Since it is "the meaning of experience and not the ontological structure of the objects which constitutes reality, reality is dependant upon the attentional structures of the conscious. ${ }^{19}$ Following Bergson, Schütz ascribes to the lifeworld the highest degree of attention, the "wide-awakeness," 20 and to the dream-world the lowest degree, a merely "passive attention."21 By characterizing "wide-awakeness" with reference to "normal [...] adults", 22 Schütz distinguishes the lifeworld from fantasy worlds - which he also regards as characteristic for children—and from worlds of (pathological) insanity. I will be adopting this point of reference, along with the attention toward external objects, as a criterion for the lifeworld's intuitive orientation, and will be using Husserl's concept of perception in order to fine-tune it to this orientation.

In order to revoke the privileged status of the lifeworld, it is necessary to abandon the ranking of attentional intensities as a means of individuating cognitive styles. The principally equal justification of cognitive styles implies that they have equivalent possibilities for validity claims upon reality. By no means, however, does this undermine the necessity of the criterion of tension of consciousness. For all cognitive styles remain "names [...] of one and the same consciousness, and it is the same life [...], which is attended to in different modifications."'?3

${ }^{15}$ Ibid., 265.

${ }^{16}$ This presentation of the criterion catalogue follows Schiemann (2002), 86ff.

${ }^{17}$ Schütz (1971), Vol. 1, 243ff. and 265, in the original not emphasized, as for all further characterizations of the criteria.

${ }^{18}$ Ibid., 243.

${ }^{19}$ Ibid., 264 (393).

${ }^{20}$ Ibid., 265.

${ }^{21}$ Ibid., 244.

${ }_{22}^{2}$ Schütz and Luckmann (1979), 47

${ }^{23}$ Schütz (1971), Vol. 1, 297. 
Taking part in the "stream of consciousness" is thus a necessary condition for cognitive styles that could not otherwise determine the experiential space of one individual with varying intensities and duration.

2. The next criterion is concerned with different contents of attention, and captures the "prevalent form of spontaneity" within a cognitive domain. ${ }^{24}$ Unlike the tension of consciousness, which refers to an internal attitude, it marks out a relation between the subject's working and the experiences she takes to be real. The distinctions among forms of spontaneity arise from the qualitative experiential differences between thinking and conducting [Verhalten], and between acting [Handlung] and not acting. Among the forms of thinking action, for example, fantasizing differs from contemplation by virtue of the absence of any intention to make the fantasy real. ${ }^{25}$ Moreover, dreaming lacks a structuring of action, as the subject does not have the freedom to direct the flow of events. ${ }^{26}$ Hence, dreaming is neither an experience of being conducting nor one of performing actions. The paradigm of a subject performing actions is the lifeworld. As already noted, its prevalent spontaneity is, for Schütz, working [Wirken].

Following Oswald Schwemmer, I would like to further restrict the spontaneity prevalent of the lifeworld by pointing to its unprofessionality. Lifeworldly action can "just as well be performed by and expected of others as from us," since we "attribute competency in principle to everyone." 27 With this further characteristic, the scope of lifeworldly action becomes far narrower, and the lifeworld loses its status as universal mediator for communication among the cognitive domains. This characterization can probably be connected with the following, negative, criterion of the "epoché."

3. Although the word "epoche" is borrowed from Husserl, Schütz uses it in a different way, namely to refer to the bracketing or suspending of particular aspects of reality ${ }^{28}$ Schütz adds a hierarchization, similar to that of the tensions of consciousness, when he claims that it is only in the lifeworld that all doubts about reality are suspended and it is accepted as self-evident. ${ }^{29}$ Nevertheless, this ranking does not lead to the privileging of the lifeworld, as the doubts about the validity of reality in other domains of experience apply only to particular phenomena. To formulate it as a paradox: the general epoché of the lifeworld, which is characterized by a complete absence of doubt, is the specifically lifeworldly epoché. For other domains of meaning, Schütz himself introduces examples of specific epochés: thus, dreaming experience is not concerned with the validity of

\footnotetext{
${ }^{24}$ Ibid., 265.

${ }^{25}$ Ibid., 270.

${ }^{26}$ Ibid., 277.

${ }^{27}$ Schwemmer (1987), 207.

${ }^{28}$ Schütz (1971), Vol. 1, 263 and 265

${ }^{29} \mathrm{Ibid} ., 265$ and 268.
}

"certain logical axioms"30; scientific reflection puts aside, among other aspects, the bodily existence of the researcher "as psycho-physical human being". ${ }^{31}$

4. While the characteristics mentioned so far have to do with the subjective constitution of objects and meaning, the next one introduces the specific "form of sociality" 32 as a further definitional feature. Roughly speaking, it distinguishes the domains of meaning that are experience exclusively alone (e.g., dreams, contemplation) from those that can be experience only together (e.g., lifeworld) also from those that can be experienced alone or together (e.g. fantasy, religion and according to Schütz, science). On Schütz's view, as I will elucidate further below, the familiar/well-known essence of lifeworldly social forms results from a minimalization of the typification of social relations.

5. Possibilities for the production of complex relational networks within and between domains of meaning are opened up by the two final criteria: "time-perspectives" and "experiencing one's self." 33 The criterion of different "time-perspectives" is closely tied to the aforementioned criterion of sociality. It refers to the objective time of the world that is beyond control, to biological times (bodily rhythms, seasons, etc.), to individual biographical time, to the subjective time of the stream of consciousness with internal duration, and to the social time of the calendar and standardized intersubjective time. ${ }^{34}$

6. The criterion of "experiencing one's self," 35 which I merely mention here, postulates the emergence of patterns of personal identification that are specific to different domains of meaning and that are dependent upon validity elements to reality.

\section{The Lifeworld as a Restricted Perceptual World}

Three of the characteristics formulated by Schütz can be conceived as necessary criteria for the lifeworld's cognitive style: "wide-awakeness" as a specific tension of consciousness; the prevalent form of spontaneity characterized by unprofessional action that is directed toward objects within the perceptual field of an individual; and the specific epoché that places the validity of reality beyond doubt. ${ }^{36}$ The lifeworldly form of sociality discussed by Schütz, namely familiar/well-known

${ }^{30}$ Ibid., 279.

${ }^{31}$ Ibid., 286.

${ }^{32}$ Ibid., 265.

${ }^{33}$ Ibid., 265.

${ }^{34}$ Schütz and Luckmann (1979), Vol. 1, 73.

${ }^{35}$ Schütz (1971), Vol. 1, 265

${ }^{36}$ The concept of a context of lifeworldly experience, which draws upon Husserl and Schütz, has been elucidated further in Schiemann (2005), chapter 1.1.2. Along with a given background knowledge, the three criteria form a sufficient condition for lifeworldly experience, cf. ibid. Chapter 1.1.2, paragraph 3.1.2 
intersubjectivity, does not in my view count among the necessary criteria, since individuals (such as Robinson Crusoe) can also live alone in a lifeworld. Insofar as an individual has a perceptual world bound to its body, that perceptual world determines the familiarity and intuitiveness of the things that can be altered by direct (unprofessional) actions. What an individual of course conceives as a uniform world constitutes a subjective lifeworld, around which are concentrically arranged spheres of what can only be experienced indirectly. There are as many subjective lifeworlds as there are normal adult individuals, and as many shared lifeworlds as made possible by the integration of different subjective worlds into unified worlds in social action spaces.

In order to give a more precise characterization of the lifeworldly tension of consciousness, the next step will be to base the specific epoché upon Husserl's notion of perception. Lifeworldly attention has to do primarily with perception of the outer world of bodies that is not symbolically mediated. This characterization will make it possible for me to apply Schütz's and Luckmann's layered model for specifying the prevalent forms of spontaneity, time-perspective, and sociality.

The absence of - or freedom from-doubt leads to the emergence of a core of unshakable certainties, the objects of which are not any particular contents but the validity of the world. This self-evident world-belief is what Husserl refers to as a "general thesis of the natural attitude" [Generalthesis der natürlichen Einstellung]. ${ }^{37}$ The lifeworld is unquestioningly accepted as a unity and as existence that is independent of the act of knowing. Husserl's general thesis is to a certain extent within the Cartesian tradition, insofar as the given world that corresponds to this natura attitude is primarily conceived as being given to intuition. Where reflection abou experience or knowledge does not occur, it is the testimony of perception that dominates. The lifeworld is the "world of perception," because it is a world that is taken as self-evident in its being. "Perception," refers exclusively to the "mode of self-presence" of an appearing object, which Husserl calls the "original mode of intuition," [Urmodus der Anschauung] in contrast to the recollective or anticipatory intuition of a currently absent object. ${ }^{39}$ This "originally giving" [originär gebende experience is oriented toward "mere bodiliness." 40 "Through sight, touch, audition, etc., bodily things are simply there for me in the different ways appropriate to the various senses and in some particular spatial distribution." ${ }^{41}$ In this sense, the lifeworld encompasses the things within the visible surroundings of the subject that are currently present and point as signs to an Other. In a broader sense, it also extends to things that are invisible, occluded or absent at the moment but are present in memory in a "conscious sense" [bewußtseinsmäßig]. ${ }^{42}$

${ }^{37}$ Husserl (1977), 63f--also emphasized in the original.

${ }^{38}$ Husserl (1976), 49f., 171; Husserl (1968), 58f.

${ }^{39}$ Husserl (1976), 107.

${ }^{40}$ Husserl (1948), 54.

${ }^{41}$ Husserl (1977), 57.

${ }^{42}$ Ibid.
Husserl applies the general thesis not only to the "world of things" [Sachenwelt]. The same world is there "in the same immediacy as world of values, world of goods, practical world." ${ }^{43}$ In the lifeworld, bodies do not appear independently of their cultural, social and practical evaluations-and neither, in turn, do these evaluations attain an autonomous existence: "In order for something to be given as usable, beautiful, terrible, frightful, attractive or whatever else, it must be somehow present to the senses." ${ }^{44}$ The perception of meaning presupposes the perception of bodies, which is why the lifeworld remains, even from a socio-cultural perspective, primarily a world of perception. ${ }^{45}$

In subscribing to the assumption of bodily primacy, I conceptualize the lifeworld as a cognitive style that is founded upon the achievements of outer perception. Schütz and Luckmann have used the term "stratifications" [Aufschichtungen] to refer to the structures of such a domain of experience. I will be using this model in order to specify the circle of necessary conditions for a restricted social context. In so doing, I will be pursuing the strategy of limiting the scope of the claims to validity of the definitions I am borrowing from Schütz and Luckmann in order to make space for consideration of experientially different contexts. The spatial stratification specifies the prevalent spontaneity of direct action that is characteristic of the lifeworld and which takes on foremost significance in a world of perception. Schütz and Luckmann, who characterize the lifeworld through socially mediated as well as through immediate experience, follow the same ranking. The temporal and social stratifications confirm the structural features of the spatial stratification and provide additional definitions.

\subsection{Spatial Stratification}

The centerpoint of the spatial structure is the locus of the bodily presence of the lifeworldly subject. The scope of its direct actions spans the so-called "primary zone of efficacy" [primäre Wirkzone]. This zone contains all the things and people that the subject can influence solely through bodily movement (within a present that spans a certain time interval)-including the use of technical devices (tools, means of locomotion, etc.). A "secondary zone of efficacy" [sekundäre Wirkzone] includes the use of technical devices to alter bodies outside of the primary zone. The primary zone is entirely, and the secondary zone partially, within the sphere of perceptible things. The "world currently within reach" [Welt der aktuellen Reichweite], which is made up of these two zones, can be divided according to sensory modalities (what is visible in the distance can only seldom be smelled, whereas what can be smelled generally has a broader spatial range than what can be touched or tasted, etc.).

${ }^{43}$ Ibid., 59-emphasized also in the original.

${ }^{44}$ Husserl (1948), 53.

${ }^{45}$ Ibid., 55. 
It bordersupon the "worldpotentiallywithin reach [WeltderpotentiellenReichweite]," which includes objects that are not currently present but can be in the future. ${ }^{46}$

The notion of spatial stratification can be illustrated with the example of a student's domestic workspace (which may be sufficiently similar to Husserl's rather inadmissibly tidy lifeworld): her primary zone of efficacy includes the computer she was just using a moment ago as well as the part of the speaker and door opener she is presently using. The secondary zone of efficacy contains visible and invisible things: the door-opening mechanism itself (invisible), the front door (partially visible) and the person outside who just rang the doorbell (invisible). Along with the inventory of the primary zone of efficacy, the world that is currently within the student's reach also contains perceptible objects outside of the action-radiusincluding, for example, objects that her gaze falls upon outside the window (houses across the street, distant stretches of landscape). It does not however include the person who has not yet entered, although this person may be part of the world potentially within reach. None of these worlds contains invisible components of mechanical-electronic devices, such as keyboards and speakers, unless the user has an interest in their function and would thus draw them into the world potentially or even currently within her reach. As far as modern technical devices are concerned, the lifeworld is a world of button-pushing. It is only concerned with relevant in- and outputs, and does not normally extend beyond the surface of technical apparatuses.

\subsection{Temporal Stratification}

The temporal structures of the lifeworld that Schütz and Luckmann investigate are exceedingly complex, and can be contrasted with other closed domains of meaning by virtue of the flowing together of otherwise separate forms of time. ${ }^{47}$ The spatial stratification in fact already implies the basic structure of the temporal stratification: the present occurs primarily in the world that is currently within reach; future events and (shared) experiences make up the world that is potentially within reach.

The state of the world beyond its potentially reach effects a subject in a different way temporally than spatially. Whatever is spatially out of reach tends to escape her interest and also her knowledge. Lifeworlds, in their essential locality, are only marginally involved with distant events. Of the events that are temporally out of reach, however, there are two that have unconditional significance for individual subjects: one's own birth and death. One cannot have any direct lifeworldly contact with these events ${ }^{48}$ One knows about them only through the accounts of others, and assumes that one's own birth and death must be similar to those of others. Of course,

${ }^{46}$ Schütz and Luckmann (1979), Vol. 1, 63ff.

${ }^{47}$ Ibid., $73 \mathrm{ff}$.

${ }^{48}$ Ibid., 74 f. the mediacy of these experiences is not symmetrical. One's own birth is far more removed from one's experience than one's death, which announces its approach in bodily aging and dying.

For Husserl, Schütz and Luckmann, the transcendence of birth and death is the basis of the strict generational orientation of a lifeworldly context, in which much older and much younger people appear only at the margins. The zenith of efficacy of one's predecessors, which is manifest in cultural achievements, belongs to the past, while the coming generation participates in adult life only partially.

\subsection{Social Stratification}

According to Schütz's and Luckmann's starting premise, each individual subject assumes unquestioningly "that other men exist." 49 The social stratification deals with a differentiation of social experience according to degrees of anonymity: anonymity stands in, so to speak, an inversely proportional relation to the immediacy of experience, while no social experience is so immediate that it could do entirely without the application of anonymous definitions. "Anonymity" refers to typologies that are applied to people, i.e. the formation and use of types for identifying people ("our mailman Mr. Martin," "an enemy of the people," etc.). ${ }^{50}$ It concerns aspects of actions less in the primary zone of efficacy than in the world potentially within reach.

For Schütz and Luckmann, the reach of the socially stratified lifeworld fades off into indeterminacy. They impute not only the weakest but even the strongest forms of mediacy of social experience to the lifeworld, which retains its midpoint but extends to the entire social and cultural world. Such radical openness corresponds, on the one hand, to the horizonedness [Horizonthaftigkeit] of lifeworldly experience, on the other hand it precludes a classification of social experience in which lifeworldly experience stands alongside other kinds of experience. In contrast to Schütz and Luckmann, I would therefore like to apply the criterion of anonymity in such as way as to highlight the part of the social world that is already restricted by the spatial stratification. Anonymity should deliver definitions that make it possible to distinguish at least roughly between people with whom one shares a lifeworld and people who appear in one's lifeworld but do not properly belong to it. In carrying out such a demarcation, it is possible to build upon Schütz's and Luckmann's conception of the lifeworld as a world of perception. Experience in which anonymity is as minimal as possible can only be had, according to Schütz and Luckmann, in "face-to-face situation," i.e. through bodily presence. The term for one subject's attentively turning to the other is the "thou-orientation," and the other who is experienced as an equal person is a "fellow being" [Mitmensch].

${ }^{49}$ Ibid., 87

${ }^{\text {so }}$ On lifeworldly typologies, cf. Schiemann (2005), chapter 1.1.2, paragraph 3.1.2 
Whenever this orientation is mutual, the social relationship can be called a "we-relationship." 1

We-relationships can be classified according to the degree of anonymity. The more concrete, detailed and presumably also persevering an unmediated social relationship is, the less important typologies become in the "thou-orientation." 52 The alter ego may appear as a singular individual that cannot be captured adequately by any typology at all. Higher degrees of anonymity arise through the successive replacement of immediate social experience by typologies. In the extreme case, typologies can fully take the place of social experience. Since we-relationships depend upon a turning of attention for which typologies can provide no substitute, they are progressively destroyed by increasing anonymity. It is in we-relationships with minimal degrees of anonymity that I see the essential social feature of the shared lifeworld.

\subsection{A Proto-Concluding Characterization}

As a world of perception, the subjective and the shared lifeworlds have a centric nature. The shared lifeworld, which has been the focus here, appears to individuals as a familiar social space in which they linger sometimes with more attention and sometimes with less, but which they can also sometimes leave and to which they can again return. One knows the objects and people in one's lifeworld on their own terms. That is the way in which they remain in one's memory when they are no longer present or when one is outside of one's lifeworld (while dreaming or fantasizing, while being in public, at work, etc.). Other spaces of experience are layered upon the lifeworld in varying degrees of familiarity, and partially overlap with it. Persons, which enter the lifeworldly domain coming out of these spaces of experience, remain distincted from the lifeworld at first. Since everything that belongs to the lifeworld must be perceptible, its temporal modus is essentially the present. The past is the source the experiences come that make perception possible and orientate action, and it is toward the future that desires, expectations and action plans are directed.

As an equal cognitive style alongside others, the lifeworld does not lose its foundational significance for the conceptualization of processes of modernization Increasing professionalization can only be understood against the backdrop of the existing unprofessional spaces of experience, which find their very core in the re-defined lifeworld. Moreover, the integration of the lifeworld into a manifold of differing domains of meaning offers the possibilities for conceiving of the lifeworld as a cultural phenomenon that arises only within a plurality of historically changing lifeworlds. The cultural-historical process of differentiation of experience leads to a multiplication of non-lifeworldly cognitive styles.

\footnotetext{
${ }^{51}$ Schütz and Luckmann (1979), Vol. 1, 90f.

${ }^{52}$ Ibid., $95 \mathrm{ff}$.
}

\section{Examples of Non-Lifeworldly Cognitive Styles}

Using examples of two non-lifeworldly experiences-experimental natural science and subjectivity-I would now like to discuss the application of Schütz's criterion catalogue to the demarcation of different cognitive styles. Schütz and Luckmann never mention these two experiential contexts as closed domains of meaning. Only in a few places do they speak-very generally-about science and about the "scientific contemplation" that they impute to science. ${ }^{53}$ Without being able to give any convincing justification, Schütz contrasts the latter with the lifeworld. Moreover, his understanding of scientific contemplation has less in common with cognitive styles found in the sciences than with Husserl's concept of subjective experience. ${ }^{54}$

Since Schütz and Luckmann do not consider subjectivity as a closed domain of meaning, they overlook the constitutive significance that this cognitive style has for modern self-understanding. In his persuasive study of modern forms of identity, Charles Taylor refers to what he calls the three "sources of the self": alongside the "voice of nature" and the "affirmation of ordinary life" that is bound up with the lifeworld, there is also the "inwardness" that characterizes the demarcation of reason from the outside world as well as its formation as an autonomous site of knowledge and action. ${ }^{55}$ The mainstream discourse on subjectivity in early modernity got underway with a ritual turning away from the lifeworld, which opened up newfound space for loneliness. ${ }^{56}$ Subjectivity soon became the subject of methodological analyses, which subsequently influenced introspective procedures in psychology (Wundt, James, Titchener and the Würzburg school with Külpe) as well as phenomenological method of reduction (Husserl). ${ }^{57}$ Finally, it has, as a space of sensory qualities, experienced an unanticipated renaissance in the past few decades in the philosophy of mind..$^{58}$

\subsection{Experimental Natural Science}

Schütz's concept of a cognitive style offers the possibility of a classification within the plurality of modern modes of experience in the first approximation. Thus, the uniform characterization of the experience that is characteristic for experimental science is also only sensible by virtue of the contrast to other cognitive styles.

\section{${ }^{53}$ Ibid., 48f., 356ff.; Schütz (1971), Vol. 1, $281 \mathrm{ff}$.}

${ }^{54} \mathrm{Cf}$. Schiemann (2002).

${ }^{55}$ Taylor (1992), 109ff., 207ff. I use the concept of modernity here in a sense that encompasses modernity in its contempary period; cf. Schiemann (2009).

${ }^{56} \mathrm{Cf}$. Bürger (1998)

${ }^{57}$ Varela and Shear (1999).

${ }^{58}$ Smith and Thomasson (2005); Kriegel and Williford (2006) 
It cannot claim to do justice to the diversity of scientific methods, domains and conceptions. A conceptual demarcation of experimental science is of crucial importance. These disciplines have been a-perhaps the-motor driving the scientification and technologization that is characteristic of modernity.

Experimental procedures in the natural sciences present a context of purposiverational action, which aims to state or to create phenomena, and serves to develop, evaluate or criticize knowledge of objectifiable reality. ${ }^{59}$ It is found in just about all natural sciences and can be invoked as their defining feature. The term "phenomenon" here refers to events, processes or states that are expected or that have been demonstrated to admit of conceptual description, to appear regularly under the appropriate conditions, and to accessible to theoretical explanation. In a broader sense, it can also (or alternatively) be used to refer to regularity itself. Thus, the experimental creation of phenomena need not impose any particular conception upon them. Countless phenomena have indeed been discovered in experiments that were not devised with that aim. In general, it can be said that the minimization of parameters and variables that is necessary for the systematic investigation of phenomena necessitates a demarcation of the objects of the experiment from their surroundings. In order to fulfill this condition optimally, experiments are often conducted in technically manipulable apparatuses. Experimental phenomena are perceived or observed. "Perception" refers to the acquisition of sensory impressions from external bodies, such as also are encountered in the lifeworld. "Observation," on the other hand, is the empirical referral to theoretical entities (electrons, atoms, genes, black holes, etc.) that is mediated by the apparatus. Many scientific experiments have to do with properties that are too small, too large, too distant or too transient for perception. If observations can be made with the help of or through measurement devices, sensory perception may be limited to reading information from dials or other presentations of results, i.e. interchangeable representations of data of theoretical entities. Observations, however, are also mediated by the senses insofar as they arise through actions. The ongoing automatization of experimental techniques has however made forms of observation possible that are only peripherally or not at all dependent upon human perception.

The aforementioned condition of demarcation from the surroundings allows for a spatio-temporal localization of experiments. Its intended claim to validity is, however, not local but universal. Scientific knowledge is supposed to be testable under reproducible conditions, and stakes a claim upon unrestricted intersubjective validity. This claim to universality is matched by the boundary expanding structure of research organizations. The bearers of experimental science are not single individuals but the worldwide, networked "scientific communities" of the various disciplines. The knowledge they produce has only a relative objectivity, though, insofar as experimental science-like science in general-is essentially a sociocultural endeavour. Hence, scientists follow changeable and replaceable "though styles" (Ludwik Fleck) in their beliefs, or they organize their work within

${ }^{59}$ For overviews of recent literature on experimentation, see Heidelberger and Steinle (1988); Radder (2002). changeable and replaceable "paradigms" (Thomas S. Kuhn). Under these historically contingent conditions, the predominant rationality of the experimental sciences has proven itself to be instrumental. It answers, roughly speaking, partly to the inner dynamics of acquisition of knowledge through problem-solving, partly to the external societal factors that support or hinder the development of methods and investigations of object-domains.

This admittedly rather rudimentary description of experimental science can be re-formulated and made more precise with the terminology of Schütz's criterion catalogue. Experimental science shares the "wide-awakeness" of acting subjects that is characteristic of the lifeworld and inscribed in the first criterion of tension of consciousness. But this attentional intensity can in the context of experiments be directed to things that function as signs for results that cannot themselves be accessed perceptually, as the discussion of observation showed. It follows that the spatial structure of experimental design does not necessarily point back to perceptual conditions. Rather, it varies with institutional, methodological and object-dependent requirements. The spectrum can span from a narrowly bounded locality up to an earth encompassing global level. Modern communication systems make it possible to carry out experiments, if necessary, in spatially very disparate locations, and to evaluate the data somewhere else altogether. The second criterion, too, is relatively independent of the reach of an individual's perceptual field: the prevalent spontaneity of experimental action is directed toward the design, the execution and the evaluation of experiments, as well as to the development and application of the attendant conceptual and theoretical constructions. Successful experiments demand a high-degree of professionalism in practical and systematic respects, which is normally guided by thought styles or paradigms. As an example of the specific epoché, the third criterion, Schütz mentions the bracketing of the bodily existence of the researcher as a "psycho-physical human being" (see above). The form of sociality, the fourth criterion, describes the organization in "scientific communities." If the experimental praxis also requires an ability that may resemble lifeworldly forms of action, the claim to universality, on the other hand, requires the interchangeability of acting subjects. Finally, the definitions discussed so far, and the limits of their applicability to the diversity of varieties of experimental science, are reflected in the final criterion of specific time-perspectives. A common element could be portrayed more closely with Hans Blumenberg's concept of "world-time" as "core of all conceivable chronologies" and contrasted with the "life-time" typical of everyday praxis. ${ }^{60}$

\subsection{Subjectivity}

Subjective experience is experience in which a subject's attention is directed toward her own conscious events or states in experiencing or reflecting upon them Husserl's transcendental epoché is one example of subjective experience, as are the forms of affective involvement (Betroffenheit) and of self-consciousness with

${ }^{60}$ Blumenberg (1986) 
self-attribution described by Hermann Schmitz. ${ }^{61}$ People to whom subjective experience is ascribed have privileged access to that experience. Their reports have the status of uncorrectability, and are given in the first-person singular. The features of the corresponding cognitive style are related in a partially complementary fashion to those of the lifeworld. ${ }^{62}$

The direction of the tension of consciousness is, so to speak, contrary to that of the lifeworld: in the lifeworld, attention is directed toward external objects of perception, whereas, in the case of subjectivity, it is directed to one's own conscious states (sensations, perceptions, thoughts, attitudes, moods, etc.), which are withdrawn from their everyday, practical meaning. Whereas the locus of bodily presence is the immovable midpoint of the spatial structure of the lifeworld, it can be left aside in subjective experience. Thoughts that are not tied up with perception and sensations are free of the necessity of a spatial localization. It is possible to go to a particular location merely in thought, or to be lost in thought and forget one's actual physical location. While the prevalent spontaneity of a person in the lifeworld aims toward specific intervention in an external world that is shared with fellow human beings, in subjective experience it is conducted as an invisible act within the inner world of consciousness, and doe not primarily have an agentive but, rather, an experiential or a reflective character Professionalism, which need not be present in the lifeworld, can indeed be formed in subjectivity. Individual awareness of one's own inwardness does not presuppose any specific competency, because the possibility of its realization is an integral componen of modern self-understanding. But, on the other hand, the methods of introspection and phenomenological reduction, which are available for systematic mental selfexploration, must be acquired through learning and practice. The subjective epoché does not bracket out doubts about the reality of external objects but the practical goals that are prominently bound up with them in other worlds. The questions that arise within a subjective cognitive style are not concerned with properties of perceived objects that are relevant for action but with the experiential qualities, thoughts or propositional attitudes that are connected with perception, how their mode of presentation depends upon spatio-temporal position, etc. With respect to its form of sociality, subjective experience is not communalized but essentially lonesome experience, and not limitlessly shareable with other people. Time-perspectives, finally, focus upon dimensions of inner time-consciousness that are not at issue within the lifeworld.

\section{Conclusion}

In order to illustrate Schütz's conception of cognitive styles, I have discussed three domains of meaning that are of significance for modern processes of differentiation of experience: the lifeworld can be seen as the core of unprofessionalized spaces

\section{${ }^{61}$ Schmitz (1990).}

${ }^{62}$ The definitions belonging to a subjective context of experience were developed in Schiemann (2005), Chap. 1.2.2, and are discussed critically in relation to Schütz's concept of "scientific contemplation" in Schiemann (2002) of experience, experimental natural science is to be regarded as a central motor driving scientification and technologization, subjectivity is foundational for human self-understanding today.

The three areas, however, also have particular relevance for phenomenological analysis. Traditionally, the phenomenology of the lifeworld coming from Husserl has been accorded a foundational role in two senses: it has been thought to present the foundation of human experience in general and of scientific knowledge in particular. Against this characterization, which conflicts with the currently predominant plurality of experience, I have drawn upon Schütz in order to establish not only the lifeworld but also experimental science as autonomous contexts.

Husserl was right in pointing out that the analysis of the lifeworld must avail itself of a perspective external to the lifeworld. This insight must be generalized in two respects. Every analysis of a domain of experience requires a reference point that does not lie in the domain. The plurality of experience delivers just such reference points by bringing out the differences among various cognitive styles. Subjectivity - the decisive domain of meaning for the phenomenological analysis of the lifeworld-is among them. Subjectivity is no more a privileged context than the lifeworld. It is not the "subjectivity that creates all world-validities with their contents and in all pre-scientific and scientific ways." ${ }^{63}$ Rather, it corresponds to a cognitive style that other experiences do not require exclusively for their validity. It owes its existence to an attitude that can be taken by anyone, with or without practice, and which can be more or less beneficial ${ }^{64}$ Subjectivity is in this sense a generally accessible cognitive style, but one that can be experienced only individually and which is typical for modern self-understanding.

\section{References}

Blumenberg, Hans. 1986. Lebenszeit und Weltzeit. Frankfurt am Main: Suhrkamp. Bürger, Peter. 1998. Das Verschwinden des Subjekts: eine Geschichte der Subjektivität von Montaigne bis Barthes. Frankfurt am Main: Suhrkamp.

Embree, Lester (ed.). 1999. Schützian social science. Dordrecht: Kluwer.

Endress, Martin, George Psathas, and Hishashi Nasu (eds.). 2004. Explorations of the life-world: Continuing dialogues with Alfred Schütz. Dordrecht: Kluwer.

Grathoff, Richard, and Walter M. Sprondel (eds.). 1979. Alfred Schütz und die Idee des Alltags in den Sozialwissenschaften. Stuttgart: Ferdinand Enke.

Heidelberger, Michael, and Friedrich Steinle (eds.). 1988. Experimental essays - Versuche zum Experiment. Baden-Baden: Nomos Verlagsgesellschaft.

Heller, Agnes. 1986. The sociology of everyday life. In Sociology, vol. 2, ed. Ulf Himmelstrand. London: Sage.

${ }^{63} \mathrm{Husserl}$ (1976), 70.

${ }^{64}$ Husserl compares the change in attitude that occurs in the transition from the natural to the transcendental attitude with the change in attentional directedness that "normal people" make when they move from lifeworldly occupations ("father") to their jobs ("shoemaker") or to politics ("citizen") (ibid., 139ff., 154), i.e. when they cross the boundaries separating domains of experience. 
Husserl, Edmund. 1948. Erfahrung und Urteil. Untersuchungen zur Geneologie der Logik. Hamburg: Claassen \& Goverst.

Husserl, Edmund. 1968. In Husserliana IX: Phänomenologische Psychologie. Vorlesungen Sommersemester 1925, ed. Walter Biemel. The Hague: Nijhoff.

Husserl, Edmund. 1976. In Husssrliana VI: Die Krise der europäischen Wissenschaften und die transzendentale Phänomenologie. Eine Einführung in die phänomenologische Philosophie, ed. Walter Biemel. The Hague: Nijhoff.

Husserl, Edmund. 1977. In Husserliana III/1: Ideen zu einer reinen Phänomenologie und phänomenologischen Philosophie, Erstes Buch: Allgemeine Einführung in die reine Phänomenologie 1. Halbband, ed. Karl Schuhmann. The Hague: Nijhoff.

Kant, Immanuel. 1900ff. In Kant's gesammelte Schriften, ed. Königlich Preußischen (later the Deutschen) Akademie der Wissenschaften (zu Berlin) (Berlin 1900ff). Vol. V.

Kriegel, Uriah, and Kenneth Williford (eds.).2006.Self-representationalapproaches to consciousness. Cambridge, MA: MIT Press.

List, Elisabeth, and Ilja Srubar (eds.). 1988. Alfred Schütz: Neue Beiträge zur Rezeption seines Werkes. Amsterdam: Rodopi.

Natanson, Maurice (ed.). 1970. Phenomenology and social reality. The Hague: Nijhoff.

Radder, Hans (ed.). 2002. The philosophy of scientific experimentation. Pittsburgh: University of Pittsburgh Press.

Schiemann, Gregor. 2002. Rationalität und Erfahrung. Ansatz einer Neubeschreibung von Alfred Schütz' Konzeption der, Erkenntnisstile. In Zugänge zur Rationalität der Zukunft, ed. Nicole C. Karafyllis and J.C. Schmidt. Stuttgart: Metzler.

Schiemann, Gregor. 2005. Natur, Technik, Geist. Kontexte der Natur nach Aristoteles und Desccartes in lebensweltlicher und subjektiver Enfahrung. Berlin: de Gruyter.

Schiemann, Gregor. 2009. Hermann von Helmholtz's mechanism: The loss of certainty. A study on the transition from classical to modern philosophy of nature. Dordrecht: Springer.

Schmitz, Hermann. 1990. Der unerschöpfliche Gegenstand. Bonn: Bouvier.

Schütz, Alfred. 1971. Gesammelte Aufsätze, vol. 1. The Hague: Nijhoff.

Schütz, Alfred. 1973. Collected Papers, vol. I: The problem of social reality. The Hague: Nijhoff. Schütz, Alfred, and Luckmann Thomas. 1979. Strukturen der Lebenswelt, vol. 1. Frankfurt am Main: Suhrkamp.

Schwemmer, Oswald. 1987. Handlung und Struktur. Zur Wissenschaftstheorie der Kulturwissenschaften. Frankfurt am Main: Suhrkamp.

Smith, D.W., and A.L. Thomasson (eds.). 2005. Phenomenology and philosophy of mind. Oxford/ New York: Clarendon Press/Oxford University Press.

Srubar, Ilja. 1988. Kosmion. Die Genese der pragmatischen Lebenswelttheorie von Alfred Schütz und ihr anthropologischer Hintergrund. Frankfurt am Main: Suhrkamp.

Taylor, Charles. 1992. Sources of the self: The making of the modern identity. Cambridge: Cambridge University Press.

Varela Frances J., and J. Shear (eds.) 1999. The view from within: First-person approaches to the study of consciousness. Journal of Consciousness Studies 6(2-3): 1-14.

\section{The Infinite Science of the Lifeworld: Steps Toward a Postfoundational Phenomenology}

Giovanni Leghissa

Abstract This essay considers the problem of historicity together with the paradoxes of foundation. The concept of lifeworld has been studied mainly in order to clarify two orders of problems, the first concerning the relationship between history and the lifeworld, the second concerning the paradoxes contained in the Krisis regarding the possibility to attain a new foundation of transcendental phenomenology. Both issues must be taken into consideration before we question the possibility of a science of the lifeworld.

\section{The Problem of Historicity and the Paradoxes of Foundation}

The concept of lifeworld has been studied mainly in order to clarify two orders of problems, the first concerning the relationship between history and the lifeworld, the second concerning the paradoxes contained in the Krisis regarding the possibility to attain a new foundation of transcendental phenomenology. Both issues must be taken into consideration before we question the possibility of a science of the lifeworld.

On the one hand, starting from Ricoeur's and Landgrebe's pioneering essays,' much attention has been paid to the problem of historicity. The aim was not to show how Husserl, a philosopher with strong interests in mathematics, succeeded in structuring a coherent philosophy of history at the end of his career, after decades

\section{'Ricoeur (1949), Landgrebe (1963, 1968, 1982).}

G. Leghissa ( $(凶)$

Dipartimento di Filosofia e Scienza dell'educazione, University of Turin,

Via Sant'Ottavio, 20, Torino 10124, Italy

e-mail: giovanni.leghissa@unito.it 


\section{CONTRIBUTIONS TO PHENOMENOLOGY}

IN COOPERATION WITH

THE CENTER FOR ADVANCED RESEARCH IN PHENOMENOLOGY

Volume 70

Series Editors:

Nicolas de Warren, Katholike Universiteit Leuven, Belgium

Dermot Moran, University College Dublin

Editorial Board:

Lilian Alweiss, Trinity College Dublin, Ireland Elizabeth Behnke, Ferndale, WA, USA Michael Barber, St. Louis University, MO, USA

Rudolf Bernet, Husserl-Archief, Katholieke Universiteit Leuven, Belgium David Carr, Emory University, GA, USA

Chan-Fai Cheung, Chinese University Hong Kong, Chin James Dodd, New School University, NY, USA

Lester Embree, Forida Atlantic University, FL, USA Alfredo Ferrarin, Università di Pisa, Italy

José Huertas-Jourda, Wilfrid Laurier University, Canada

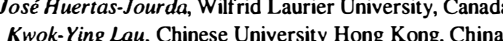

Nam-In Lee, Seoul National University, Kor

Dieter Lahmar, Universiät zu Köln Geran

William R.McKenma Miami University, OH, US

Algis Mickunas, Ohio University, OH, USA

J.N. Mohanty, Temple University, PA, USA

Junichi Murata, University of Tokyo, Japan

Thomas Nenon, The University of Memphis, TN, USA

Thomas M. Seebohm, Johannes Gutenberg-Universität, Germany Gail Soffer, Rome, Italy

Anthony Steinbock, Southern Illinois University at Carbondale, IL, USA

Shigeru Taguchi, Yamagata University, Japan

Dan Zahavi, University of Copenhagen, Denmark

Richard M. Zaner, Vanderbilt University, TN, USA

$$
\text { Scope }
$$

The purpose of the series is to serve as a vehicle for the pursuit of phenomenological research across a broad spectrum, including cross-over developments with other fields of inquiry

to Phenomenology has published nearly 60 titles on diverse themes of phenomenological philosophy. In addition to welcoming monographs and collections of papers in established areas of scholarship.

the series encourages original work in phenomenology. The breadth and depth of the Series reflects the rich and varied significance of phenomenological thinking for seminal questions of human inquiry as well as the increasingly international reach of phenomenological research.

Babette Babich • Dimitri Ginev

Editors

\section{The Multidimensionality of Hermeneutic Phenomenology}

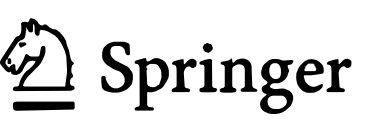

